\title{
Tolerância de microrganismos eucariotos ao herbicida glifosato
}

\section{Tolerance of eukaryotic microorganisms to glyphosate herbicide}

\author{
Osvaldo Manuel Nuñez Noguera ${ }^{1}$, John Lennon Goulart Salgueiro ${ }^{2}$, \\ Edimara Aparecida Francisco ${ }^{3}$, Júlia Ronzella Ottoni ${ }^{4}$, \\ Michel Rodrigo Zambrano Passarini ${ }^{5}$
}

\begin{abstract}
Resumo
O glifosato é um herbicida amplamente utilizado. A Organização Mundial da Saúde (OMS) reclassificou o glifosato como "provavelmente cancerígeno a humanos". A remoção do glifosato do ambiente pode ser realizada por ação enzimática microbiana. O presente trabalho enfocou o isolamento de microrganismos do solo capazes de tolerar glifosato como única fonte de carbono. As células foram isoladas em meio de cultivo mínimo suplementado com glifosato. Foram isoladas 17 bactérias, 14 fungos e 1 levedura. Foi verificada a produção da biomassa microbiana na presença e na ausência do glifosato. Um fungo (F3) e uma levedura (L1) foram selecionados após teste de tolerância ao glifosato em meio líquido. Os microrganismos toleraram o glifosato, entretanto, o metabolismo foi afetado pelo herbicida, comparado ao controle sem glifosato. Estatisticamente, o tempo de crescimento apresentou diferenças significativas. Microrganismos eucarióticos isolados de solo com glifosato são tolerantes ao composto e podem ser úteis como biorremediadores de ambientes afetados por este herbicida.
\end{abstract}

Palavras-chave: Fungo filamentoso. Levedura. Bactéria. Solo. Biorremediação.

${ }^{1}$ Mestrando no Programa de Pós-graduação em Biociências da Universidade Federal da Integração Latino-Americana (UNILA), Foz do Iguaçu, Paraná, Brasil.

${ }^{2}$ Bacharelado em Engenharia Agronômica pelo Centro Universitário Dinâmica das Cataratas (UDC), Foz do Iguaçu, Paraná, Brasil. Engenheiro na Innova Agrotecnologia, Foz do Iguaçu, Paraná, Brasil.

${ }^{3}$ Doutorado em Produção Vegetal pela Universidade Federal do Tocantins (UFT), Palmas, Tocantins, Brasil. Gerente de Produção na Innova Agrotecnologia, Foz do Iguaçu, Paraná, Brasil.

${ }^{4}$ Doutorado em Genética e Biologia Molecular pela Universidade Estadual de Campinas (Unicamp), Campinas, São Paulo, Brasil. Professora Visitante no Instituto Latino-Americano de Ciências da Vida e da Natureza (ILACVN) da Universidade Federal da Integração Latino-Americana, Foz do Iguaçu, Paraná, Brasil.

${ }^{5}$ Doutorado em Genética e Biologia Molecular de Micro-organismos pela Universidade Estadual de Campinas, Campinas, São Paulo, Brasil. Professor no Instituto Latino-Americano de Ciências da Vida e da Natureza da Universidade Federal da Integração Latino-Americana, Foz do Iguaçu, Paraná, Brasil. E-mail: michel.passarini@unila.edu.br 


\begin{abstract}
Glyphosate is one of the most widely used herbicides. The World Health Organization (WHO) has reclassified glyphosate as "probably carcinogenic to humans". Glyphosate removal from the environment can be performed by microbial enzymatic action. The present work focused on the isolation of soil microorganisms that can tolerate glyphosate as the sole carbon source. Cells were isolated in minimal culture medium supplemented with glyphosate. Microbial biomass production was verified in the presence and absence of glyphosate. Seventeen, fourteen and one bacteria, fungi and yeast were isolated, respectively. One fungus (F3) and one yeast (L1), were selected after glyphosate tolerance test in liquid medium. Eukaryotic microorganisms tolerate glyphosate, however metabolism was affected by herbicide compared to control without glyphosate. Statistically growth time showed significant differences. Eukaryotic microorganisms isolated from soil with glyphosate are tolerant to the compound and may be useful as bioremediators of environments affected by this herbicide.
\end{abstract}

Keywords: Filamentous fungi. Yeast. Bacteria. Soil. Bioremediation.

\section{Introdução}

Nos últimos anos, com o aumento populacional descontrolado, as populações ao redor do planeta vêm necessitanto cada vez mais da demanda de diversas variedades de cultivares agrícolas. Essa necessidade faz com que as atividades agroindustriais venham a ficar mais dependentes do uso de defensivos agrícolas, os quais são responsáveis em eliminar as diversas pragas que devastam as lavouras em numerosas fazendas espalhadas pelo mundo.(1) Os herbicidas representaram cerca de $45 \%$ dos agrotóxicos comercializados em todo o mundo, pois a grande maioria das culturas agrícolas se tornou dependente do uso dessas substâncias, tais como soja, milho, arroz e algodão, entre outras. ${ }^{(2,3)}$ Apesar de sua grande relevância, com o aumento e a qualidade da produção agrícola, esses compostos podem se tornar uma importante fonte de contaminação para o ambiente e para o homem, quando liberados indiscriminadamente nas áreas de cultivo devido à falta de controle e/ou descarte adequado. ${ }^{(4)}$

Entre os herbicidas mais comumente aplicados, o glifosato ( $\mathrm{N}$-fosfonometil)glicina) vem sendo usado na remoção de ervas daninhas, principalmente nas culturas geneticamente modificadas. Este agrotóxico vem ganhando popularidade, pois nos últimos anos levantaram suspeitas de suas possíveis propriedades cancerígenas, ganhando mais peso quando a Organização Mundial da Saúde (OMS) reclassificou o glifosato como "provavelmente cancerígeno para os seres humanos". ${ }^{(5)}$

O glifosato, um análogo aminofosfônico do aminoácido natural glicina, é amplamente utilizado como herbicida para o controle de gramíneas anuais e perenes ou ervas daninhas de folhas largas. ${ }^{(6)}$ Este composto inibe a 5-enolpiruvatoshikimato3-fosfato sintase (EPSPS), uma enzima que impede a biossíntese de ácidos aromáticos. $^{(3,7)}$ Esta rota não está presente em animais, fazendo com que o glifosato seja considerado um dos defensivos menos tóxicos utilizados. Entretanto, existem evidências de que este composto pode levar a danos hepatorrenais em camundongos e diminuição da biodiversidade de microrganismos de amientes aquáticos e terrestres. Existem relatos que o composto pode afetar a microbiota intestinal das abelhas, causando alterações comportamentais e até a morte, bem como proporcionar distúrbios da microbiota intestinal de animais, os quais vivem perto de áreas agrícolas. ${ }^{(8,3,9,10,11)}$

Para a saúde humana, o glifosato é amplamente distribuído nos ossos, fígado e nos rins, com tempo de excreção via metabolismo hepático em 7 dias. ${ }^{(12)}$ Em trabalho realizado em 2017, foi verificado que mais de $50 \%$ das amostras de urina coletadas entre 2001 e 2015 de humanos 
jovens na Alemanha continham concentrações de glifosato e ácido aminometilfosfônico (AMPA), seu principal metabólito, acima do nível permitido $\left(0,1 \mu \mathrm{g} \mathrm{L} \mathrm{L}^{-1}\right){ }^{(13)}$ Segundo Rendon-Von et al., ${ }^{(14)}$ foram detectadas concentrações acima do nível nas amostras de águas subterrâneas e na urina de agricultores da cidade de Hopelchén (México). Estudos demonstraram que o glifosato pode ser um fator que contribui para os defeitos congênitos observados em populações humanas que vivem perto de regiões agrícolas plantadas com cultivares tolerantes ao glifosato. ${ }^{(15,16)}$

Uma estratégia para remediar ambientes com a presença do glifosato é a utilização de microrganismos recuperados de ambientes já contaminados, como o solo exposto ao herbicida. A comunidade microbiana presente neste solo contaminado pode se adaptar à presença do composto e desenvolver mecanismos de tolerância e/ou degradação do glifosato, evidenciando o potencial do isolamento de microrganismos a partir destes ambientes. Os microrganismos podem metabolizar o glifosato de duas maneiras: i) excisão da ligação carbono-fósforo, resultando na formação de fosfato e sarcosina (via da CP liase), por exemplo, em Pseudomonas spp., que podem utilizar o fosfato; $i$ ) clivagem oxidativa da ligação C-N no lado carboxila, catalisada pela glifosato oxidoredutase (GOX), resultando na formação de ácido aminometilfosfônico (AMPA) e glioxilato (via AMPA). ${ }^{(17,18)}$ Estudos anteriores evidenciaram a capacidade de microrganismos recuperados de solos contaminados com herbicidas de se desenvolverem na presença de grifosato em ensaios in vitro. As linhagens bacterianas que apresentaram melhor capacidade de degradar esse composto foram identificadas como pertencentes aos gêneros Burkholderia e Pseudomonas. ${ }^{(19,20)}$

Nesse sentido, a utilização de células microbianas isoladas de solos contaminados com o herbicida glifosato pode ser considerada uma ferramenta promissora na biorremediação deste poluente, visto que estas células podem estar adaptadas à presença do composto, uma vez que este ainda vem sendo utilizado nas lavouras brasileiras. Dessa forma, o presente trabalho teve como foco principal o isolamento e a seleção de microrganismos tolerantes ao herbicida, a partir de amostras de solos, com alta frequência de pulverização com glifosato, na região da cidade de Foz do Iguaçu, no estado do Paraná, Brasil, objetivanto a utilização das linhagens tolerantes ao glifosato em futuros processos de biorremediação de ambientes contaminados com este herbicida.

\section{Material e Métodos}

Coleta e processamento das amostras de solo

A coleta das amostras de solo pulverizadas com glifosato foi realizada no dia 30 de agosto de 2019, na região de Foz do Iguaçu, estado do Paraná, Brasil (Figura 1), em áreas utilizadas com cultivo de milho. Foram coletados dois tipos de amostras de solo: $i$ ) solo com aplicação de glifosato realizada há 30 dias; ii) solo com aplicação de glifosato realizada há 1 ano. Ambos os pontos de coleta são pulverizados com o herbicida, com uma frequência de 6 vezes ao ano. A amostragem foi realizada a 5 metros da borda das culturas, em uma profundidade de $20 \mathrm{~cm}$ no solo, com auxílio de uma picareta. Cerca de $20 \mathrm{~g}$ de cada solo (uma amostra de cada tipo de solo), foram transferidos para tubos de $50 \mathrm{~mL}$ de plástico esterilizados, sendo armazenados a $4{ }^{\circ} \mathrm{C}$.

Para o processamento inicial das amostras, cerca de $20 \mathrm{~g}$ de cada solo foram transferidos, separadamente, para frascos contendo $100 \mathrm{~mL}$ de água destilada esterilizada. As amostras foram agitadas com auxílio de um bastão de vidro por 1 minuto (dispersão das células microbianas das partículas do solo). As amostras foram diluídas em série $\left(10^{-1}, 10^{-2}\right.$ e $\left.10^{-3}\right)$, e alíquotas de $50 \mu 1$ foram inoculadas em placas de Petri contendo os meios de cultivo descritos a seguir, com modificações. ${ }^{(21,22)}$ As amostras foram processadas no Laboratório de Biotecnologia Ambiental da Universidade Federal da Integração Latino-Americana (UNILA). 
Figura 1 - Coleta das amostras de solo na região de Foz do Iguaçu, Paraná. A: glifosato aplicado há 1 ano (latitude -25.5468; longitude -54.5284); B: glifosato aplicado há 30 dias (latitude -25.5224; longitude -54.5280). Círculos pretos indicam os locais das coletas.

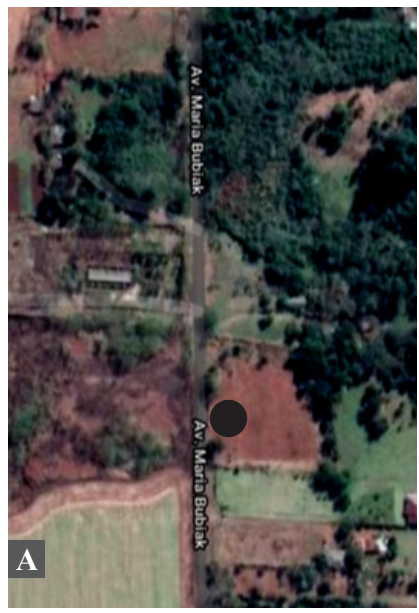

Fonte: Google Maps

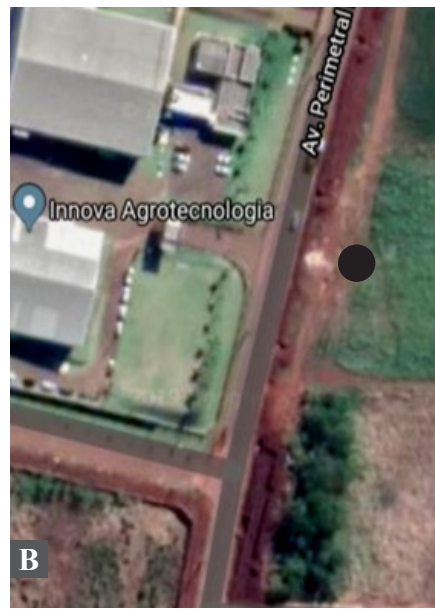

Meios de cultivo e isolamento

Os meios de cultivos utilizados no estudo foram: $i$ ) meio para isolamento (MI): peptona $1 \mathrm{~g}$ $\mathrm{L}^{-1}, \mathrm{~K}_{2} \mathrm{HPO}_{4} 0.5 \mathrm{~g} \mathrm{~L}^{-1}, \mathrm{MgSO}_{4} .7\left(\mathrm{H}_{2} \mathrm{O}\right) 0.2 \mathrm{~g} \mathrm{~L}^{-1}$, glifosato $10 \mathrm{~g} \mathrm{~L}^{-1}$, ágar $1.5 \mathrm{~g} \mathrm{~L}^{-1}$, adicionados 200 $\mathrm{mg} \mathrm{L}^{-1}$ de cloranfenicol para isolamento de fungos filamentosos e $100.000 \mathrm{UI} \mathrm{L}^{-1}$ de nistatina para isolamento de bactérias; ii) meio para purificação de bactérias (MPB): extrato de levedura $2.0 \mathrm{~g} \mathrm{~L}^{-1}$, peptona $5.0 \mathrm{~g} \mathrm{~L}^{-1}, \mathrm{~K}_{2} \mathrm{HPO}_{4} 0.5 \mathrm{~g} \mathrm{~L}^{-1}, \mathrm{MgSO}_{4} .7\left(\mathrm{H}_{2} \mathrm{O}\right)$ $0.2 \mathrm{~g} \mathrm{~L}^{-1}$, ágar $1.5 \mathrm{~g} \mathrm{~L}^{-1}$; iii) meio para purificação de fungos (MPF): infusão de batata $4.0 \mathrm{~g} \mathrm{~L}^{-1}$, dextrose $20.0 \mathrm{~g} \mathrm{~L}^{-1}, \mathrm{~K}_{2} \mathrm{HPO}_{4} 0.5 \mathrm{~g} \mathrm{~L}^{-1}, \mathrm{MgSO}_{4} .7\left(\mathrm{H}_{2} \mathrm{O}\right) 0.2 \mathrm{~g}$ $\mathrm{L}^{-1}$, ágar $1.5 \mathrm{~g} \mathrm{~L}^{-1}$. Alíquotas de $50 \mu \mathrm{lde}$ cada amostra $\left(10^{-1}, 10^{-2}\right.$ e $\left.10^{-3}\right)$ foram inoculadas aos meios de cultivo em triplicata. As placas foram mantidas a $37^{\circ} \mathrm{C}$ e $28{ }^{\circ} \mathrm{C}$ durante 3 e 5 dias, para bactérias e fungos, respectivamente. As colônias formadas foram coletadas e transferidas para os meios de purificação, sendo armazenadas a $4{ }^{\circ} \mathrm{C}$.

Triagem inicial de células tolerantes ao glifosato

Todas as células isoladas foram submetidas ao teste inicial. Os isolados foram transferidos com auxílio de uma alça de platina, para tubos de ensaio contendo $3 \mathrm{~mL}$ do meio de cultivo MI, sem adição de ágar. Os tubos foram mantidos em incubadoras a $37^{\circ} \mathrm{C}$ e $28^{\circ} \mathrm{C}$, por 3 e 5 dias, para bactérias e fungos, respectivamente, a $150 \mathrm{rpm}$. Um tubo de ensaio controle contendo meio MI sem adição de glifosato foi preparado para cada linhagem. O crescimento microbiano no meio de cultivo contendo glifosato foi considerado um resultado positivo. Os isolados positivos foram selecionados e utilizados no teste de produção de biomassa na presença do glifosato.

Ensaio da influência do glifosato na produção de biomassa microbiana

Dois microrganismos (1 fungo filamentoso F3 e 1 levedura - L1) foram considerados isolados positivos no teste de triagem de células tolerantes ao glifosato, sendo submetidos à avaliação quanto à produção de biomassa. Os isolados foram crescidos em meio MPF, sem e com ágar, durante 2 e 5 dias a $28{ }^{\circ} \mathrm{C}$, para a levedura e para o fungo filamentoso, respectivamente. $\mathrm{O}$ crescimento da levedura foi verificado em espectrofotômetro e padronizado na concentração pela densidade ótica (D.O.) de 0.08, a $600 \mathrm{~nm}$. Assim, $50 \mu 1$ do crescimento microbiano leveduriforme e dois discos de diâmetros $(0,5 \mathrm{~mm})$ contendo o micélio do fungo filamentoso foram transferidos para Erlenmeyers de $50 \mathrm{~mL}$, contendo 
$30 \mathrm{ml}$ dos meios de cultivo MI, sem adição de ágar, separadamente. O experimento foi realizado em triplicata. Foram preparados controles com os meios MPB e MPF para a levedura e para o fungo, respectivamente, sem adição de glifosato. Os frascos foram mantidos em incubadoras a $28{ }^{\circ} \mathrm{C}$, por 3 e 5 dias (levedura) e durante 5 a 6 dias (fungo filamentoso), a $150 \mathrm{rpm}$.

Análise do peso seco da biomassa microbiana

Para análise do peso seco, foram utilizadas as triplicatas das amostras descritas no item anterior, de acordo com Batista et al. ${ }^{(23)}$ Os meios de cultivo com as células de levedura foram centrifugados a $10.000 \mathrm{rpm}$ por 10 minutos, em centrífuga refrigerada, em tubos de $50 \mathrm{~mL}$ previamente secos e pesados. O líquido sobrenadante foi descartado, e o tubo foi submetido à secagem a $70{ }^{\circ} \mathrm{C}$ em estufa de secagem. $\mathrm{O}$ meio de cultivo contendo o micélio fúngico foi filtrado em um filtro de $0.22 \mu \mathrm{L}$ previamente seco e pesado, por filtração à vácuo. $\mathrm{O}$ papel de filtro contendo o micélio foi submetido à secagem a $70{ }^{\circ} \mathrm{C}$ em estufa de secagem. O tubo e o papel de filtro, ambos com as células microbianas (sem umidade), foram pesados e a diferença do peso do tubo e do papel sem células e com células (após as etapas de centrifugação, filtração e secagem), foram calculadas de acordo com a fórmula acima:
Peso seco = massa do tubo/papel seco (com célula) - massa do tubo/papel seco (sem célula).

\section{Análises estatísticas}

As análises estatísticas como a variância (ANOVA) e teste de Tukey (com 5\% de probabilidade) da produção de biomassa microbiana (triplicata) foram realizadas utilizando o software estatístico PAST versão $3.26 \mathrm{~b}$ para Windows, ${ }^{(24)}$ modificado.

\section{Resultados}

\section{Microrganismos isolados}

Após coleta das amostras de solo e isolamento dos microrganismos, ao todo 32 isolados foram recuperados, entre eles 9 bactérias, 1 levedura e 8 fungos filamentosos da amostra de solo com 1 ano da aplicação de glifosato, bem como 8 bactérias e 6 fungos filamentosos da amostra de solo com 30 dias da última aplicação de glifosato. A Figura 2 mostra as placas do isolamento de microrganismos oriundas de ambas as amostras, sendo possível a observação de uma maior incidência de crescimento microbiano nas placas de isolamento a partir da amostra de solo coletado após 1 ano de aplicação do herbicida (Figura 2A, 2B, 2E e 2F).

Figura 2 - Placas mostrando o isolamento dos microrganismos a partir das amostras de solo. Bactérias isoladas da amostra de solo coletado após 1 ano de aplicação com glifosato (A, B) e 30 dias $(\mathrm{C}, \mathrm{D})$. Fungos e leveduras isolados da amostra coletada após 1 ano de aplicação com glifosato $(\mathrm{E}, \mathrm{F})$ e 30 dias $(\mathrm{G}, \mathrm{H})$. Diluição $10^{-3}$.
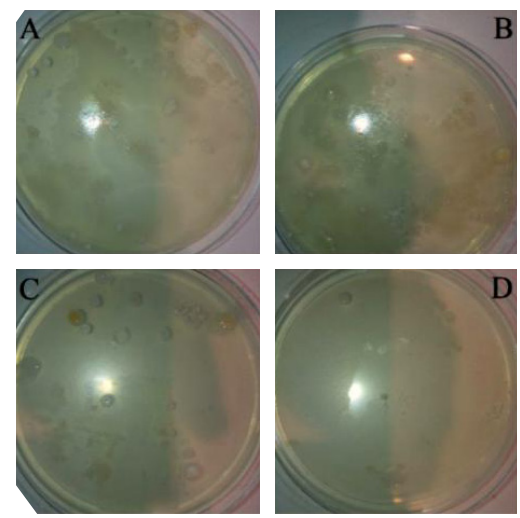
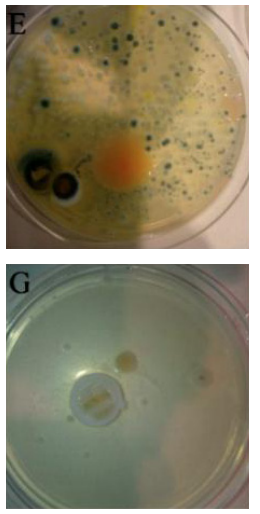

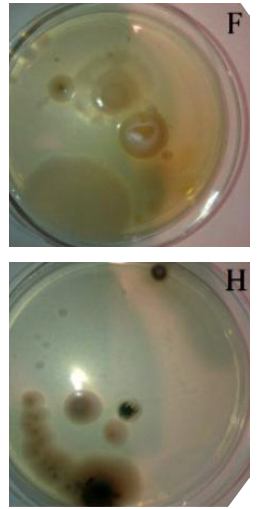

Fonte: Autores 
Tolerância e influência de glifosato na biomassa microbiana

Após o ensaio de triagem inicial com os 32 isolados, foi selecionado 1 fungo filamentoso (F3) e 1 levedura (L1), os quais toleraram o herbicida glifosato e foram capazes de crescer na presença do composto. Os dois microrganismos foram utilizados no teste de influência do glifosato na produção de biomassa microbiana. Os resultados encontrados mostraram que houve uma diferença na produção da biomassa entre os tempos avaliados para os isolados testados, quando comparados com o controle. Os tempos avaliados foram: $i$ ) tempo 1: 4 e 5 dias de crescimento para os testes com a levedura; ii) tempo $2: 5$ e 6 dias de crescimento para os testes com o fungo filamentoso. Foi observado aumento de massa microbiana na presença do glifosato com o passar dos dias, no entanto os crescimentos não foram significativos quando comparados com os crescimentos dos controles, mostrando que o glifosato interferiu na capacidade de desenvolvimento da levedura e do fungo filamentoso in vitro (Tabela 1).

As análises estatísticas mostraram que o parâmetro estudado (crescimento microbiano nos tempos de análise), apresentou diferenças estatisticamente significativas para amostras de leveduras e fungos $(p<0,05)$ (Tabelas 1 e 2). O F calculado da levedura apresentou valor superior ao do fungo filamentoso (Tabela 2), representando uma maior dispersão entre as médias analisadas.

Tabela 1 - Análise do crescimento microbiano (biomassa - mg) para isolados estudados.

\begin{tabular}{|c|c|c|c|c|}
\hline & \multicolumn{4}{|c|}{ Tempo de crescimento } \\
\hline & \multicolumn{2}{|c|}{ Teste } & \multicolumn{2}{|c|}{ Controle (sem adição de glifosato) } \\
\hline & 4 dias & 5 dias & 4 dias & 5 dias \\
\hline \multirow[t]{2}{*}{ Levedura } & $0.0011 \mathrm{a}$ & $0.002 \mathrm{a}$ & $0.0162 b$ & $0.0316 \mathrm{c}$ \\
\hline & 5 dias & 6 dias & 5 dias & 6 dias \\
\hline Fungo & $0.0261 \mathrm{a}$ & $0.0497 \mathrm{a}$ & $0.1146 a c$ & $0.2104 b c$ \\
\hline
\end{tabular}

Nota: Peso seco significativo indicado pela letra diferente na parte horizontal, para cada parâmetro aplicado, é estatisticamente diferente entre si em um nível significativo de $95 \%$.

Fonte: Autores

Tabela 2 - Dados estatísticos do crescimento microbiano (biomassa - mg) para isolados estudados.

\begin{tabular}{|c|c|c|c|c|c|c|}
\hline & & $\begin{array}{c}\text { Soma do } \\
\text { quadrado }\end{array}$ & $\begin{array}{l}\text { Graus de } \\
\text { liberdade }\end{array}$ & $\begin{array}{l}\text { Quadrado } \\
\text { médio }\end{array}$ & $\mathbf{F}$ & $P$ \\
\hline \multirow[t]{3}{*}{ Levedura } & Entre grupos & 0,00184422 & 3 & 0,00061474 & 2387 & $3,812 \mathrm{E}-12$ \\
\hline & Dentro do grupo & $2,06 \mathrm{E}-06$ & 8 & $2,575 \mathrm{E}-07$ & & \\
\hline & Total & 0,001846628 & 11 & & & \\
\hline \multirow[t]{3}{*}{ Fungo } & Entre grupos & 0,04209 & 3 & 0,01403 & 4,198 & 0,01859 \\
\hline & Dentro do grupo & 0,0668404 & 20 & 0,00334202 & & \\
\hline & Total & 0,10893 & 5 & & & \\
\hline
\end{tabular}

Fonte: Autores 


\section{Discussão}

Trabalhos na literatura vêm utilizando a microbiota do solo para degradar o glifosato presente no ambiente. ${ }^{(25,26,27)}$ Nosso estudo objetivou o isolamento de microrganismos em meio de cultivo com glifosato como única fonte de carbono, focando em células microbianas capazes de crescer na presença deste herbicida. Assim, para otimizar nosso estudo, foram isoladas linhagens de bactérias, fungos e levedura com características morfológicas distintas, tais como cor, tamanho e aspecto das colônias (para as bactérias e levedura), bem como cor de micélio e cor de esporos (para os fungos filamentosos). Esta seleção resultou no isolamento de baixo número de microrganismos $(n=32)$. Entretanto, foi possível observar que as placas de isolamento do solo coletado após 1 ano de aplicação de glifosato apresentaram crescimento de maior número de microrganismos em comparação à amostra de solo com 30 dias de aplicação de glifosato. Esta diferença na quantidade de microrganismos isolados das duas amostras pode ser explicada pela adaptação das células microbianas frente ao herbicida glifosato, as quais necessitam de um tempo maior para que ocorra esta adaptação às condições adversas geradas pelo glifosato. Estudos vêm demonstrando diferenças no processo adaptativo microbiano frente ao glifosato. Autores observaram que o crescimento de fungos in vitro foi afetado negativamente pelo glifosato. ${ }^{(28)}$ Os autores observaram uma drástica inibição da pigmentação e da esporulação de várias espécies fúngicas quando foram submetidas a concentrações de $1 \mu \mathrm{g} \mathrm{mL} \mathrm{mL}^{-1}$ de glifosato. $\mathrm{Na}$ pesquisa realizada por Ratcliff et al., ${ }^{(22)}$ os autores observaram uma diminuição da colonização bacteriana de raízes de plantas após aplicação do glifosato em altas concentrações $(100 \mathrm{x}$ a utilizada nas lavouras). Por outro lado, no mesmo trabalho, os autores observaram poucas mudanças na estrutura da comunidade microbiana após 30 dias de utilização de glifosato em concentrações recomendadas (5 kg por ha). Dados também encontrados por Rosenbaum et al. ${ }^{(29)}$ e Allegrini et al., ${ }^{(30)}$ que, ao usarem doses recomendadas de glifosato, não observaram efeitos significativos na comunidade microbiana presente no solo.

Outro fator importante a ser considerado está relacionado à persistência do glifosato no solo. Apesar de ser um composto essencialmente imóvel, o ácido aminometilfosfônico, metabólito secundário do glifosato, se decompõe rapidamente e pode ser lixiviado, segundo Moraes e Rossi. ${ }^{(31)}$ Desta forma, mesmo tendo o herbicida a capacidade de interromper a via do ácido chiquímico, presente em bactérias e fungos, quando se liga ao solo, ele se torna inativo, perdendo suas propriedades antimicrobianas, e ficando disponível para degradação e mineralização para $\mathrm{CO}_{2}$ por microrganismos, de acordo com Lane et al.. ${ }^{(32)}$ Neste sentido, a presença de maior número de microrganismos na amostra na qual o herbicida foi aplicado há mais tempo é esperada, visto que o glifosato, que não foi lixiviado, pode ser utilizado como fonte de carbono.

Estudos vêm relatando a tolerância e degradação de glifosato por linhagens de leveduras e também fungos filamentosos. Fernandes et al. ${ }^{(33)}$ demonstraram a capacidade de 4 isolados da espécie do fungo ectomicorrízico Pisolithus spp. em tolerar elevadas concentrações variando de 32 a $254 \mathrm{mg} \mathrm{L}^{-1}$ do herbicida glifosato. Eman et al. ${ }^{(34)}$ avaliaram a tolerância ao glifosato em 45 fungos isolados de amostras de solo coletados em 11 fazendas. Entre os isolados, Aspergillus flavus, A. niger, Penicillium verruculosum e $P$. spiculisporus foram as linhagens mais tolerantes ao herbicida. Low et al. ${ }^{(35)}$ relataram uma degradação de $21 \%$ de glifosato por uma linhagem de Saccharomyces cerevisiae utilizada na fermentação de pão. No estudo realizado por Romero e colaboradores, ${ }^{(36)}$ os autores observaram que Yarrowia lipolytica e Candida krusei conseguiram degradar 42,5\% e $66 \%$ de glifosato, respectivamente, quando este composto foi adicionado como única fonte de carbono. Neste mesmo estudo, foi demonstrado que $Y$. lipolytica apresentou uma fase de atraso prolongada em seu crescimento, iniciado apenas no sexto dia de incubação, enquanto que C. krusei 
obteve uma melhor adaptação ao glifosato, iniciando seu crescimento em 3 dias de incubação. Estes dados corroboram o presente estudo, tendo em vista que a levedura isolada (L1) levou cerca de 4 dias para se adaptar ao glifosato e a começar a se multiplicar.

Assim, observando os resultados a partir dos experimentos, podemos afirmar que o crescimento celular pode ter sido influenciado pelo metabolismo microbiano de cada microrganismo. O aumento da massa microbiana decorrente do crescimento celular do tempo 1 para o tempo 2, em ambos os isolados estudados, pode ser resultado da adaptação dos microrganismos ao glifosato e da capacidade destes de utilizar o composto como fonte de carbono para seu desenvolvimento. Desta forma, os microrganismos isolados podem ser promissores se utilizados em processos de biorremediação de ambientes contaminados com herbicidas à base de glifosato.

\section{Conclusão}

A metodologia empregada no trabalho se mostrou eficiente, pois foi possível o isolamento de bactérias, fungos filamentosos e levedura de amostras de solo contaminado com glifosato. Fungos e leveduras podem adaptar-se à presença de herbicidas tóxicos como o glifosato, apresentando capacidade de crescimento e tolerância frente a esta substância. A adaptação das comunidades microbianas à presença de glifosato, bem como o comportamento deste herbicida quando atinge o solo, são favorecidos com o passar do tempo, permitindo o desenvolvimento de microrganismos após 1 ano da aplicação na lavoura com o glifosato como uma de suas fontes de carbono. Os resultados mostram que células microbianas tolerantes e adaptadas ao glifosato apresentam potencial para serem utilizadas como adjuvantes nos processos de biorremediação de solos contaminados com glifosato. Estudos futuros precisam ser realizados para avaliar a presença de genes de degradação do glifosato, bem como a formação de metabólitos menos tóxicos e mais solúveis em água.

\section{Agradecimentos}

Os autores agradecem à Universidade Federal da Integração Latino-Americana (UNILA), bem como à empresa Innova Agrotecnologia pela ajuda com a coleta das amostras.

\section{Referências}

1 Jurado AS, Fernandes MAS, Videira RA, Peixoto FP, Vicente JAF. Herbicides: the Face and the Reverse of the Coin. An in vitro Approach to the Toxicity of Herbicides in NonTarget Organisms. In: Kortekamp A, editor. Herbicides and Environment. London: InTech; 2011. p. 1-44.

2 Qasem J. Herbicides Applications: Problems and Considerations. In: Kortekamp A, editor. Herbicides and Environment. London: InTech; 2011. p. 643-4. doi: 10.5772/550.

3 Motta EVS, Raymann K, Moran NA. Glyphosate perturbs the gut microbiota of honey bees. PNAS. 2018;115(41):10305-10. doi: Org/10.1073/Pnas. 1803880115 .

4 Food and Agriculture Organization of the United Nations (FAO). World agriculture: towards 20152030 an FAO Perspective. London: Earthscan Publications; 2003.

5 Guyton KZ, Loomis D, Grosse Y, El Ghissassi F, Benbrahim-Tallaa L, Guha $\mathrm{N}$ et al. Carcinogenicity of tetrachlorvinphos, parathion, malathion, diazinon, and glyphosate. Lancet Oncol. 2015;16(5):490-4. doi: 10.1016/S14702045(15)70134-8.

6 Williams M. The Merck Index: An Encyclopedia of Chemicals, Drugs, and Biologicals. In: O'Neil MJ, editor. $15^{\text {th }}$ Edition. Cambridge: Royal Society of Chemistry; 2013.

7 Greim H, Saltmiras D, Mostert V, Strupp C. Evaluation of carcinogenic potential of the herbicide glyphosate, drawing on tumor incidence data from fourteen chronic/carcinogenicity rodent studies. Crit Rev Toxicol. 2015;45(3):185208. doi: 10.3109/10408444.2014.1003423. 
8 Shehata AA, Schrödl W, Aldin AA, Hafez HM, Krüger M. The Effect of Glyphosate on Potential Pathogens and Beneficial Members of Poultry Microbiota In Vitro. Curr Microbiol. 2013;66(4):350-8. doi: 10.1007/s00284-0120277-2.

9 Tsui M, Chu L. Aquatic toxicity of glyphosatebased formulations: comparison between different organisms and the effects of environmental factors. Chemosphere. 2003;52 (7):1189-97. doi: 10.1016/S0045-6535(03) 00306-0.

10 Balbuena MS, Tison L, Hahn ML, Greggers U, Menzel R, Farina WM. Effects of sublethal doses of glyphosate on honeybee navigation. J Exp Biol. 2015;218(17):2799-805. doi: 10.1242/jeb.117291.

11 Van Bruggen AHC, He MM, Shin K, Mai V, Jeong KC Finckh MR et al. Environmental and health effects of the herbicide glyphosate. Sci Total Environ. 2018;616(617):255-68. doi: doi.org/10.1016/j.scitotenv.2017.10.309.

12 European Food Safety Authority (EFSA). Conclusion on the peer review of the pesticide risk assessment of the active substance glyphosate. EFSA J. 2015;13(11):4302.

13 Conrad A, Schröter-Kermani C, Hoppe HW, Rüther M, Pieper S, Kolossa-Gehring M. Glyphosate in German adults - Time trend (2001 to 2015) of human exposure to a widely used herbicide. Int J Hyg Envir Heal. 2017;220(1): 8-16. doi: 10.1016/j.ijheh.2016.09.016.

14 Rendon-Von OJ, Dzul-Caamal, R. Glyphosate Residues in Groundwater, Drinking Water and Urine of Subsistence Farmers from Intensive Agriculture Localities: A Survey in Hopelchén, Campeche, Mexico. Int J Hyg Envir Heal. 2017;14(6):595. doi: 10.3390/ ijerph14060595.

15 Laborde A, Tomasina F, Bianchi F, Bruné MN, Buka I, Comba P et al. Children's Health in Latin America: The Influence of Environmental Exposures. Environ Health Perspec. 2015;123(3):201-9. doi: 10.1289/ ehp. 1408292.
16 Paganelli A, Gnazzo V, Acosta H, López SL, Carrasco AE. Glyphosate-Based Herbicides Produce Teratogenic Effects on Vertebrates by Impairing Retinoic Acid Signaling. Chem Res Toxicol. 2010;23(10):1586-95. doi: 10.1021/ tx1001749.

17 Pollegioni L, Schonbrunn E, Siehl D. Molecular basis of glyphosate resistance-different approaches through protein engineering. FEBS J. 2011;278(16):2753-66. doi: 10.1111/j.17424658.2011.08214.x.

18 Pedotti M, Rosini E, Molla G, Moschetti T, Savino C, Vallone B et al. Glyphosate Resistance by Engineering the Flavoenzyme Glycine Oxidase. J Biol Chem. 2009;284 (52):36415-23. doi: 10.1074/jbc.M109. 051631 .

19 Manogaran M, Shukor MY, Yasid, NA, Johari WLW, Ahmad SA. Isolation and characterisation of glyphosate-degrading bacteria isolated from local soils in Malaysia. Rend Fis Acc Lincei. 2017;28(3):471-9. doi 10.1007/s12210-017-0620-4.

20 Zhao H, Tao K, Zhu J, Liu S, Gao H, Zhou $\mathrm{X}$. Bioremediation potential of glyphosatedegrading Pseudomonas spp. strains isolated from contaminated soil. J Gen Appl Microbiol. 2015;61(5):165-70. doi: 10.2323/ jgam.61.165.

21 Ramos GFC, Ramos PL, Passarini MRZ, Silveira MAV, Okamoto DN, Oliveira LCG et al. Cellulolytic and proteolytic ability of bacteria isolated from gastrointestinal tract and composting of a hippopotamus. AMB Expr. 2016;6(1):17. doi: 10.1186/s13568-0160188-x.

22 Ratcliff A, Busse M, Shestak C. Changes in microbial community structure following herbicide (glyphosate) additions to forest soils. Appl Soil Ecol. 2006;34(2-3):114-24. doi: https://doi.org/10.1016/j.apsoil.2006.03.002

23 Batista E, Ottoni JR, Sartoratto A, Oliveira VM, Passarini MRZ. Hidrocarbonetos produzidos por bactérias da Antártica. Rev Biotecnol Ciênc. 2018;7(2):38-46. 
24 Ottoni JR, Silva TR, Oliveira VM, Passarini MRZ. Characterization of amylase produced by cold-adapted bacteria from Antarctic samples. Biocatal Agric Biotechnol. 2020;23: 101452. doi: https://doi.org/10.1016/j.bcab. 2019.101452

25 Andrighetti MS, Nachtigall GR, Queiroz SCN, Ferracini VL, Ayub MAZ. Biodegradação de glifosato pela microbiota de solos cultivados com macieira. R. Bras. Ci. Solo. 2014;38:164353.

26 Santos LF, Cazotti MM. Impacto do glifosato sobre os diferentes micro-organismos do solo. Duc in Altum - FASM. 2016;15(1):27-38.

27 Monteiro P, Beneduzi A, Sampaio J, Vargas LK, Lisboa B. Isolamento de linhagens bacterianas do solo capazes de crescer em altas concentrações de glifosato. Tecnol. \& Ciên. Agropec. 2017;11(3):37-42.

28 Tanney J, Hutchison L. The effects of glyphosate on the in vitro linear growth of selected microfungi from a boreal forest soil. Can J Microbiol. 2010;56(2):138-44. doi: 10.1139/w09-122.

29 Rosenbaum KK, Miller GL, Kremer RJ, Bradley KW. Interactions between Glyphosate, Fusarium Infection of Common Waterhemp (Amaranthus rudis), and Soil Microbial Abundance and Diversity in Soil Collections from Missouri. Weed Sci. 2014;62(1):71-82, 2014. doi: https://doi.org/10.1614/WS-D-1300071.1

30 Allegrini M, Zabaloy M, Gómez E. Ecotoxicological assessment of soil microbial community tolerance to glyphosate. Sci Total Environ. 2015;15(533):60-8. doi: 10.1016/j. scitotenv.2015.06.096.

31 Moraes PVD, Rossi P. Comportamento ambiental do glifosato. Sci Agrar Parana. 2010;9(3): 22-35.

32 Lane M, Lorenz N, Saxena J, Ramsier C, Dick RP. The effect of glyphosate on soil microbial activity, microbial community structure, and soil potassium. Pedobiologia. 2012;55(6):33542.
33 Fernandes MCS, Costa LS, Grazziotti PH, Grazziotti DCFS, Santos JB, Rossi MJ. Pisolithus sp. Tolerance to glyphosate and isoxaflutole In Vitro. Rev Árvore. 2014;38(3): 461-8.

34 Eman A, Abdel-Megeed A, Suliman AMR, Sadik MW, Sholkamy EN. Biodegradation of Glyphosate by fungal strains isolated from herbicides polluted-soils in Riyadh area. Int $\mathrm{J}$ Curr Microbiol App Sci. 2013;2(8):359-81.

35 Low FL, Shaw IC, Gerrard JA. The effect of Saccharomyces cerevisiae on the stability of the herbicide glyphosate during bread leavening. Lett Appl Microbiol. 2005;40(2):133-7. doi: 10.1111/j.1472-765X.2004.01633.X.

36 Romero MC, Reinoso EH, Moreno KA, Córdoba S. Biodegradation of glyphosate by wild yeasts. Rev Mex Mic. 2004;19:45-50. 